\title{
Serrated Flow Model for Metallic Glasses under Compressive Loading
}

\author{
M.A. Yousfi ${ }^{1)}$, K. Hajlaoui ${ }^{1,2) \dagger}$, Z. Tourki ${ }^{1)}$ and A.R. Yavari ${ }^{2)}$ \\ 1) Laboratoire de Mécanique de Sousse, LMS, ENISo, Université de Sousse, 4000, Sousse, Tunisia \\ 2) SIMaP-LTPCM, Institut National Polytechnique de Grenoble, 38402 Saint Martin d'Heres, France \\ [Manuscript received 20 January 2013, in revised form 27 April 2013] \\ (c) The Chinese Society for Metals and Springer-Verlag Berlin Heidelberg
}

\begin{abstract}
A rheological model is proposed that incorporates the serrated flow nature of metallic glasses. It involves the process of the nucleation, propagation and the arrest of a shear bands in the samples subjected to compressive deformation at room temperature. Numerical resolution of the constitutive equations resulting from the model is compared with the stress-strain curve obtained from in-situ nano-compression test in SEM of $\mathrm{Zr}$ based metallic glass. Parametric identification method was applied and enabled us to release the physical parameters of the model. The obtained results showed that the model is adequately valid to describe the experimental data and the almost adjustable model parameters are physically meaningful and comparable to literature.
\end{abstract}

KEY WORDS: Metallic glasses; Shear bands; Serrated flow; Rheological modelling; Nanocrystallization

\section{Introduction}

Metallic glasses (MGs) have been widely investigated due to their good mechanical properties such as extremely high strength $(\sim 2 \mathrm{GPa})$, large elastic limits $(\sim 2 \%)$, excellent superplastic formability in the supercooled liquid region (the temperature interval between the glass transition temperature $\left(T_{\mathrm{g}}\right)$ and crystallization temperature $\left(T_{\mathrm{x}}\right)^{[1-3]}$ and good corrosion resistance ${ }^{[4]}$. However, MGs generally suffer from brittle and thus catastrophic failure as they deform inhomogeneously at room temperature under quasi-static loading conditions ${ }^{[5-7]}$. Under uniaxial tension, metallic glasses can be stretched elastically to typically about $2 \%$ of strain followed immediately by shear-off fracture ${ }^{[8]}$, but in compression this material can also be deformed elastically to about $2 \%$ followed by perfect plastic deformation through a process of highly localized shearing in narrow bands that are thin layers of material being initially only

\footnotetext{
† Corresponding author. Prof., Ph.D.; Tel.: +216 73 369 500; Fax: +216 73369 506; E-mail address: khalil.hajlaoui@eniso.rnu.tn (K. Hajlaoui)
}

DOI: $10.1007 / \mathrm{s} 40195-013-0041-\mathrm{z}$
$10 \mathrm{~nm}$ thick ${ }^{[10]}$ and fail catastrophically along one dominant shear band ${ }^{[11]}$.

In recent years, the study of bulk metallic glasses (BMGs) has focused on improving their plasticity ${ }^{[12]}$. Plasticity in BMGs is often correlated by the issue rate of the shear bands. This is the case for the amorphous alloys based zirconium, copper or platinum where one records wide plastic deformation in the stress-strain curve in compression. In some cases, values of more than $50 \%$ of plastic deformation have been achieved ${ }^{[13]}$. The plastic deformation is usually presented in the form of a series of local fall and rise of the stress, the so-called "serrated flow" behaviour. This phenomenon is similar to Portevin-Le Chatelier (PLC) effect ${ }^{[14]}$ observed in certain crystalline alloys. The "serrated flow" behaviour is still not well understood and remains the subject of various investigations.

Many works suggest that the plastic deformation behaviour of monolithic amorphous alloys is closely related to formation of nanocrystals. Indeed, based on transmission electron microscopy (TEM) study, Hajlaoui et al. ${ }^{[15,16]}$ showed experimental evidences of deformation-induced nanocrystallization in shear bands. Under nanoindentation tests, Fornell et al. ${ }^{[17]}$ 


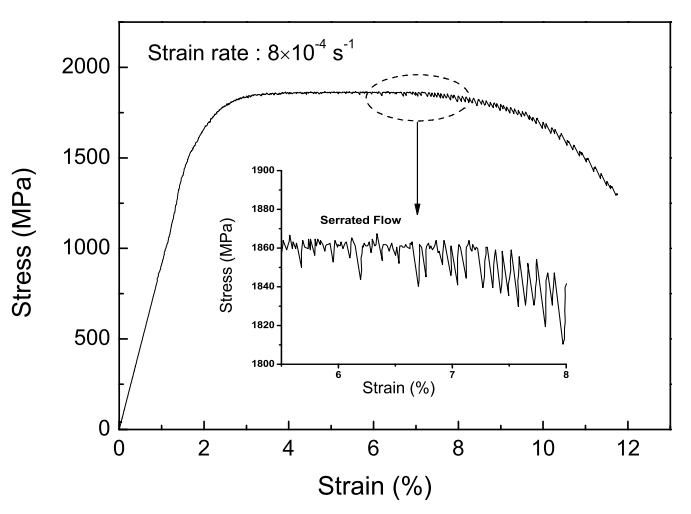

Fig. 1 Compression stress-strain curve of the $\mathrm{Zr}_{55} \mathrm{Ti}_{5} \mathrm{Al}_{7.5} \mathrm{Cu}_{22} \mathrm{Ni}_{8} \mathrm{Ga}_{2.5}$ bulk metallic glass, the inset shows an enlarged view of the serrated flow

have recently reported the formation of nanocrystallization during deformation of MGs. So, we believe that the arrest of shear banding is strongly linked with the formation of nanocrystals.

In this work, we propose a new rheological model that can capture the principal feature of shear banding and serrated flow behaviour of BMGs. Comparison with suitable experimental data of compression test allows us to identify a large number of physical model parameters.

\section{Model Formulation}

As discussed above, BMGs generally show elastic perfectly plastic behaviour in compression where the plasticity exhibits a repeated load drop and rise (serration) during continuous deformation as shown in Fig. 1. The instabilities are associated with local plastic shear slip bands as showed in Fig. 2. Serrated flow is also observed during nanoindentation, but only at slow loading rates. Activation of each individual shear band is associated with the occurrence of a discrete "pop-in" event (sudden rise in load) ${ }^{[18-22]}$.

To address these experimental observations, many micromechanism models have been proposed, the most commonly used are the free volume model $(\mathrm{FVM})^{[6,23]}$ and the shear transformation zone model $(\mathrm{STZ})^{[24]}$. They consider free volume as an order parameter and mainly describe the conditions for shear band nucleation under shear stress. Hajlaoui et al. ${ }^{[25]}$ showed via a numerical resolution of FVM constitutive equations that the shear stress drops after an initial elastic response where the free volume concentration increases significantly and assists the localization of strain in shear bands. Recently, Ye et al. ${ }^{[26]}$ and Dubach et al. ${ }^{[26]}$ have showed that the serrated flow in BMGs is connected to the individual propagation of shear band which results from the combined effects of the softening induced by shearing and structural relaxation. The repeated arrest and reactivation of shear bands have not been explained accurately. It seems that the arrest mechanism which prevents the slip of the shear bands plays a significant role in metallic glasses plasticity.

The recent microscopic observations showed in Fig. 3 revealed the presence of nanocrystallites in the vicinity of shear bands. The nanocrystallization induced by shearing has also been backed up by several authors ${ }^{[28-30]}$. These investigations have demonstrated that nanocrystals play an important role on improving the plasticity of amorphous metallic alloys by retarding sudden shear bands propagation.

\subsection{Constitutive equations of the model}

We have used the experimental observations shown in Figs. 1-3 to develop a rheological model accounting for the elementary micromecanism of the serrated flow in metallic glasses. Indeed, deformationinduced nanocrystallization observed in our previous work $^{[15,16]}$ provides a potential reason for the strain hardening mechanism. The presence of nanocrystallites in shear bands may enhance viscosity, due to the

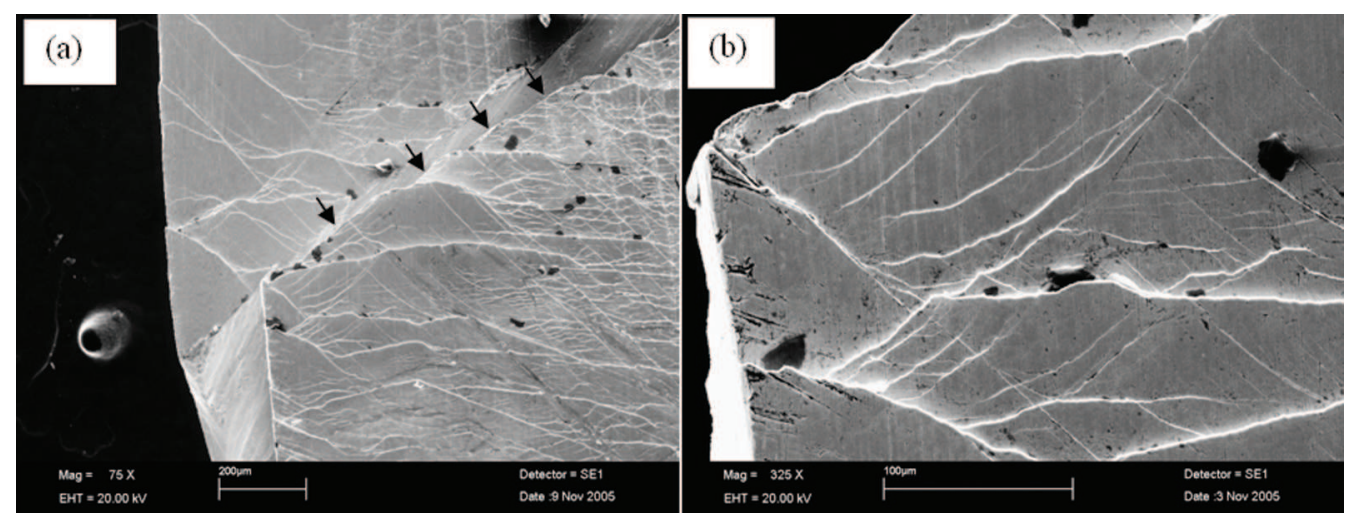

Fig. 2 SEM images of sample surface subjected to compression test: (a) a shear plan (see the arrows in the Fig. 2(a)) with emitted shear bands; (b) an enlarged image showing the dense network steps of multiple shear bands in the intensively deformed region 

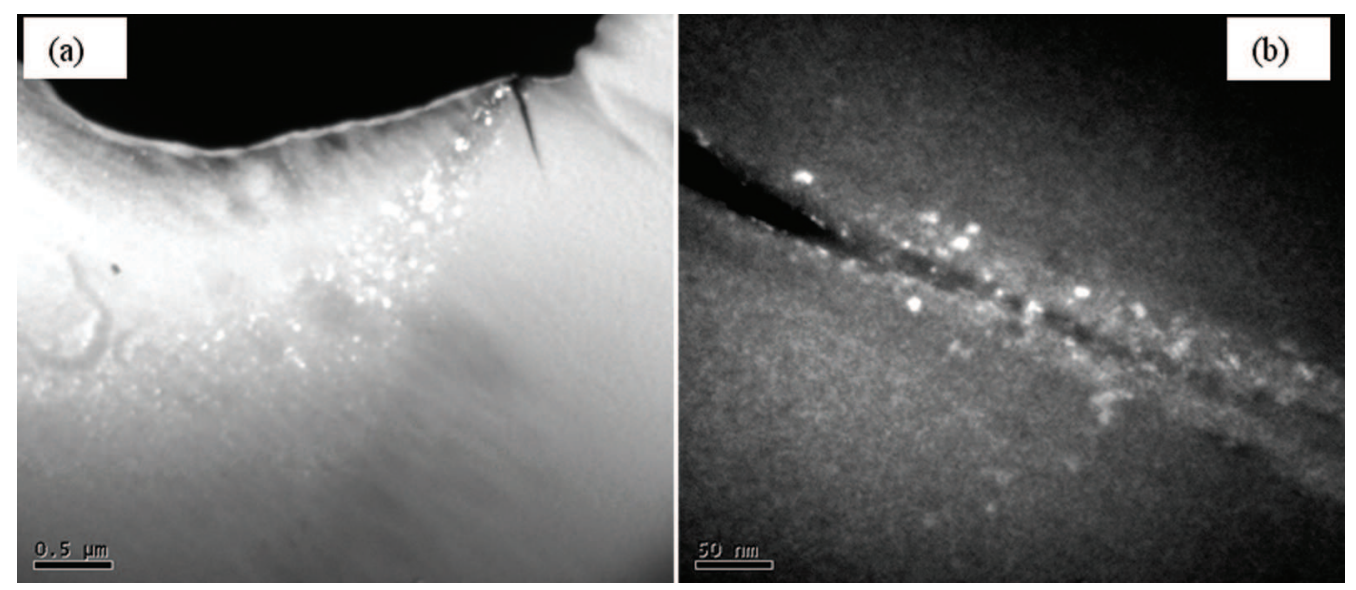

Fig. 3 TEM dark field micrographs of shear band in deformed $\mathrm{Zr}_{55} \mathrm{Ti}_{5} \mathrm{Al}_{7.5} \mathrm{Cu}_{22} \mathrm{Ni}_{8} \mathrm{Ga}_{2.5}$ bulk metallic glass: (a) nucleation of the nanocrystallites in the shear band; (b) crack widens facing a zone of nanocrystallites ahead in the already thickened shear band
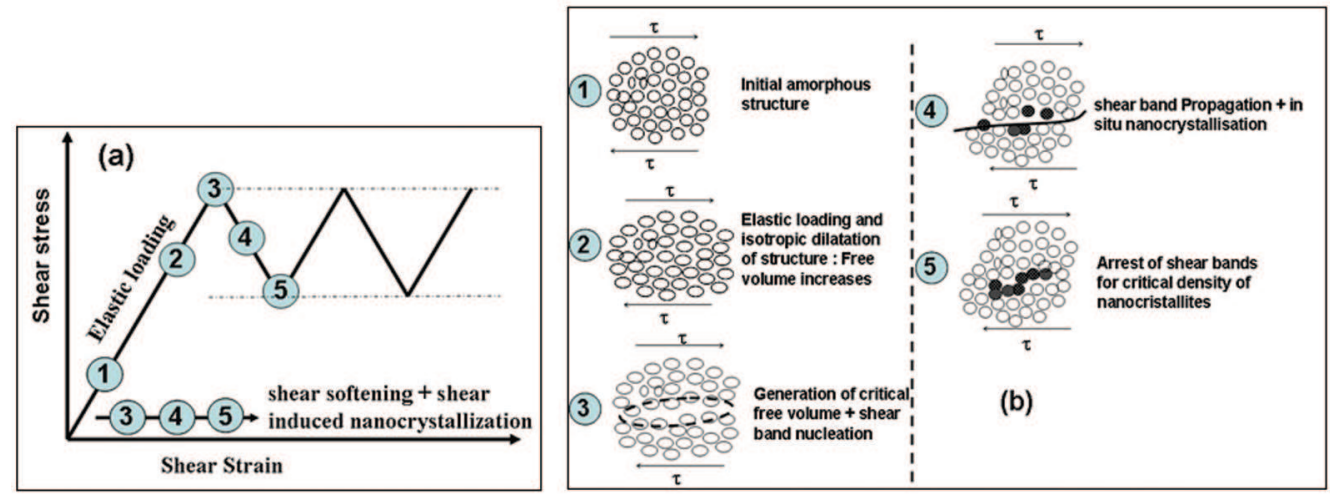

Fig. 4 Schematic illustration showing the details of the proposed model for serrated flow in metallic glasses (a) and the corresponding atomic illustrations of individual shear band propagation in nanoscale range (b)

increase of the particle content.

The proposed serrated flow rheological model is based on the fact that deformation in metallic glasses is accompanied by an increase of the 'free volume $^{,[6,25]}$. When a threshold of volume is generated, the shear band is emitted and the stress falls because the viscosity suddenly decreases in the vicinity of the band (liquid-like viscosity, $\eta_{\mathrm{s}}$ ). The process is called stress softening. The shear band propagation is accompanied by nucleation and subsequent growth of the nanocrystals. At given volume fraction of the crystals, the viscosity in the shear bands growth $\left(\eta_{\mathrm{c}}\right)$ and prevents further shearing along the bands. Fig. 4 shows the proposed microscopic mechanism for shear band behaviour, where the steps (1), (2) and (3) show elastic deformation through conventional structural dilatation mechanism and free volume creation; the steps (3) and (4) represent the shear band propagation at initial stage going with structural segregation and nanocrystallization by concentration of the shear stress; and step (5) shows the suppression of propagation and arrest of the shear band by precipitation and growth of nanocrystalline particles within the shear zone.

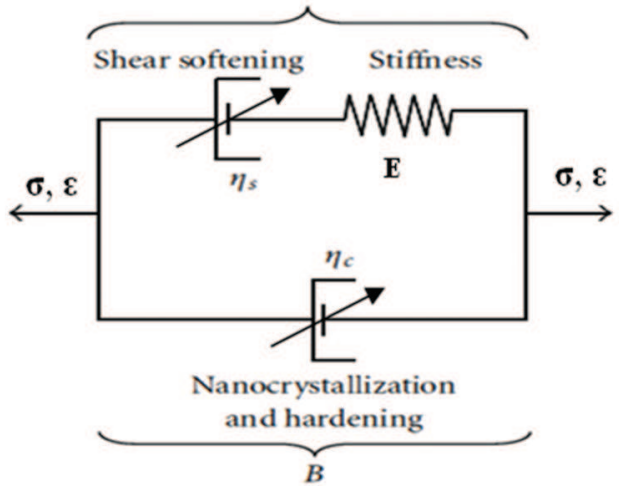

Fig. 5 Rheological model proposed for individual shear band (emission, propagation and arrest)

Fig. 5 represents the corresponding rheological model. The behaviour law resulting from the rheological model is as follows:

$$
\dot{\sigma}=\frac{E}{\eta_{\mathrm{s}}} \times\left[\left(\eta_{\mathrm{s}}+\eta_{\mathrm{c}}\right) \times \dot{\varepsilon}-\sigma\right]
$$

The equation describing the free volume evolution has 
Table 1 Model parameters of the proposed rheological model

\begin{tabular}{cc}
\hline Parameter & Designations \\
\hline$E$ & Young Modulus \\
$\dot{\varepsilon}$ & Strain rate \\
$\Delta \mathrm{G}^{*}$ & Activation energy for cristallization \\
$n$ & Avrami exponent \\
$\alpha, b_{0}, \mathrm{a}$ & Material constants \\
$\varphi_{\mathrm{cr}}$ & Critical volume fraction of particles \\
$\Delta G^{m}$ & Activation energy for atomic jump \\
$\Omega$ & Average atomic volume \\
$f$ & Attempt frequency \\
$k_{0}$ & Relaxation attempt frequency \\
$E_{\mathrm{r}}$ & Activation energy for relaxation \\
$C_{\mathrm{f}}$ & Flow defects Concentration \\
$C_{\mathrm{f}, \text { eq }}$ & Equilibrum flow defects Concentration \\
$k_{\mathrm{B}}$ & Boltzmann constant \\
$\eta_{1}, \eta_{\mathrm{s},}, \eta_{\mathrm{c}}$ & Initial viscosity, viscosity during softening and viscosity during nanocristallization \\
\hline
\end{tabular}

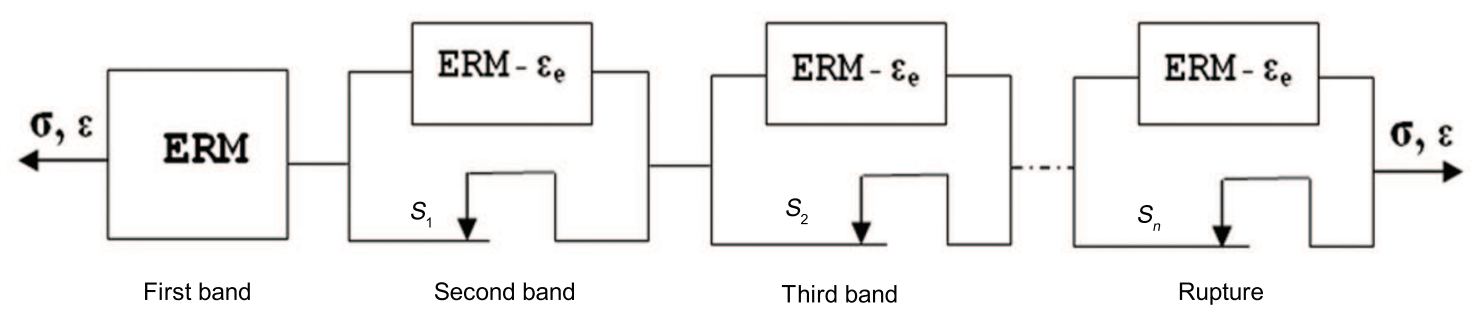

Fig. 6 Generalization of the rheological model for serrated flow behavior in metallic glasses

the form ${ }^{[6,23]}$ :

$\dot{C}_{\mathrm{f}}=-k_{0} \cdot \exp \left(-\frac{E_{\mathrm{r}}}{R \cdot T}\right) \cdot C_{\mathrm{f}} \cdot\left(C_{\mathrm{f}}-C_{\mathrm{f}, \mathrm{eq}}\right)+a \cdot \dot{\varepsilon} \cdot C_{\mathrm{f}} \cdot\left(\ln C_{\mathrm{f}}\right)^{2}$

where $\eta_{\mathrm{s}}$ is given starting from the rheological model:

$$
\eta_{\mathrm{s}}=\frac{\sigma-\eta_{\mathrm{c}} \cdot \dot{\varepsilon}}{\dot{\varepsilon}_{\mathrm{s}}}
$$

$\dot{\varepsilon}_{\mathrm{s}}=2 \cdot f \cdot C_{\mathrm{f}} \cdot \exp \left(-\frac{\Delta G^{m}}{k_{\mathrm{B}} \cdot T}\right) \cdot \sinh \left(\frac{\left(\sigma / \sqrt{3}-\dot{\varepsilon} \cdot \eta_{\mathrm{c}}\right) \cdot \Omega}{2 \cdot k_{B} \cdot T}\right)$

$\eta_{\mathrm{c}}=\eta_{\mathrm{l}} \cdot\left(1-\frac{1}{\phi_{\mathrm{cr}}} \cdot\left(1-\exp \left(-\left(b_{0} \cdot \exp \left(-\frac{\Delta G^{*}}{R \cdot T}\right) \cdot\left(\frac{\varepsilon}{\dot{\varepsilon}}\right)\right)^{n}\right)\right)\right)^{-\alpha}$

where $\eta_{\mathrm{s}}, \eta_{\mathrm{c}}$ and $\dot{\varepsilon}_{\mathrm{s}}$ describe the shear softening, the increase viscosity according to the correlation between viscosity and the fraction of nanocristal solids ${ }^{[31]}$ and the Spaepen's strain rate ${ }^{[6]}$ respectively. The model involves a large number of material parameters which are defined in the Table 1 . These parameters will be identified from suitable compressive test.

\subsection{Generalization of the model}

The proposed model shown in Fig. 5 explains the nucleation, the propagation and the arrest of individual shear band. However, in real compression test, serrations may be associated with generation of mul- tiple shear bands. Then, the model must be generalized in order to reproduce the curve of compression test with large number of the shear bands. We suppose that the total plastic strain is the addition of distinct steps-deformation induced by the slip of the each band. Fig. 6 shows the generalization process of the model, where ERM, $\varepsilon_{\mathrm{e}}$ indicate the elementary rheological model presented in Fig. 5 and the elastic strain respectively. The parameters $S_{1}, S_{2}$ and $S_{n}$ are the stress limitations for the activation of the second, third and $n^{\text {th }}$ shear bands.

\section{Results and Comparison with Experiments}

The resultant stress-strain curve is obtained by the resolution of the coupled Eqs. (1), (2), (3), (4) and (5), and the model parameters must be obtained by fitting the above equations to appropriate experimental data. Then, the constitutive model presented in the previous section can now be compared with the experimental data. We shall compare our predicted results to those of the experimental uniaxial compression results drawing tests of Dongchan et al ${ }^{[32]}$ or Chen et al ${ }^{[33]}$. This choice is based on the fact that our model is narrow to highlight the individual shear striation behavior under the assumption that each serration is associated with individual shear events. The comparison with our experimental results of Fig. 1 may not be very adequate since these results cannot give a 


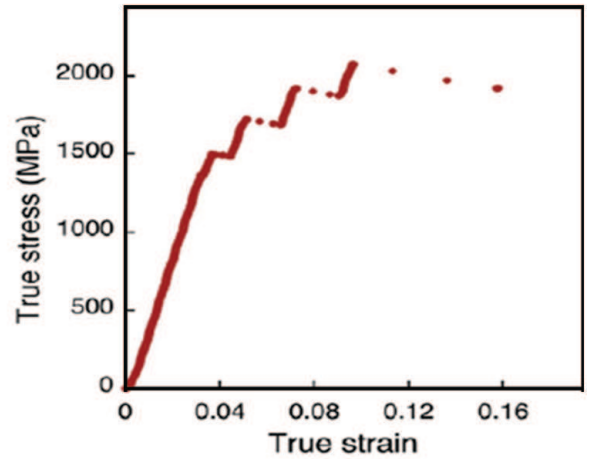

Fig. 7 Stress-strain curve during uniaxial nanocompression test on $\mathrm{Zr}_{35} \mathrm{Ti}_{30} \mathrm{Co}_{6} \mathrm{Be}_{29}$ glassy alloy ${ }^{[32]}$

direct correlation between the yields drops in the stress-strain curve and the dynamic emission and propagation of the shear bands. However, Dongchan et al. ${ }^{[32]}$ and Chen et al. ${ }^{[33]}$ conducted a nano-compression test on the $\mathrm{Zr}_{35} \mathrm{Ti}_{30} \mathrm{Co}_{6} \mathrm{Be}_{29}$ and $\mathrm{Cu}_{47} \mathrm{Ti}_{33} \mathrm{Zr}_{11} \mathrm{Ni}_{6} \mathrm{Sn}_{2} \mathrm{Si}_{1}$ metallic glasses where the samples show elastic deformation followed by a jerky type deformation with transient shear banding events registered with displacement bursts in the stressstrain curve as shown for example in Fig. 7. In these tests, only a small volume of sample is involved which is near to what we consider in our microscopic model.

The constitutive equations of our model are then fitted to stress-strain curve of Fig. 7 and the models parameters are obtained using a parametric identification method under Matlab tools. Fig. 8 shows the experimentally obtained stress-strain data of the Zrbased glassy alloy ${ }^{[32]}$, together with the best fit curve obtained on the basis of model equations. The fitting parameters are given in Table 2 .

Fig. 8 shows that the fitting route yields satisfactory results and the proposed model is well qualified to describe the serrated flow behaviour in metallic glasses. The adjustable model parameters are physically meaningful and comparable with those found in literatures. Values of $\Delta G^{m}, \Omega$ and $f$ are close to that obtained by Huang et al. ${ }^{[34]}$ and Ekambaram et al. ${ }^{[35]}$. The values of $k_{0}, E_{\mathrm{r}}, C_{\mathrm{f}, \text { eq }}$ and $a$ are in agreement with similar published results of Russew et al. ${ }^{[36]}$, Bletry et $a l .{ }^{[37,38]}$ and Van Aken et al. ${ }^{[39]}$.

The obtained activation energy for crystallization process $\Delta G^{*}$ is close to $77.2 \mathrm{~kJ} / \mathrm{mol}$. This value remains lower compared with those obtained using thermal electrical resistivity (TER) and differential scanning calorimetry (DSC) ${ }^{[40,41]}$. This is probably due to the complicate crystallization process in metallic glasses during deformation compared to what takes place during isothermal or isochronal heat treatment. Overall, the crystallization process in amorphous structure consists of nucleation and growth. During intense shearing at high temperature ${ }^{[42]}$, small activation energy of crystallization promotes the nucleation of the nanocrystals which may explain the
Table 2 Set of fitting parameters

\begin{tabular}{cc}
\hline Parameter & Value \\
\hline$\Delta G^{*}(\mathrm{~kJ} / \mathrm{mol})$ & 77.2 \\
$\Delta G^{m}\left(10^{-19} \mathrm{~J}\right)$ & 1.19 \\
$f\left(10^{13} \mathrm{~s}^{-1}\right)$ & 1.66 \\
$\Omega\left(\mathrm{m}^{3}\right)$ & $6.74 \times 10^{-29}$ \\
$k_{0}\left(10^{21} \mathrm{~s}^{-1}\right)$ & 0.52 \\
$E_{\mathrm{r}}(\mathrm{kJ} / \mathrm{mol})$ & 91 \\
$C_{\mathrm{f}, \text { eq }}$ & $1.19 \times 10^{-12}$ \\
$a$ & 0.166 \\
$b_{0}$ & 93.59 \\
$E(\mathrm{GPa})$ & 44.3 \\
$C_{\mathrm{f} 0}$ & $10^{-7}$ \\
$\dot{\varepsilon}\left(\mathrm{s}^{-1}\right)$ & $10^{-3}$ \\
$n$ & $3.89 \times 10^{-2}$ \\
$\alpha$ & 11.63 \\
$\varphi_{\mathrm{cr}}$ & 0.355 \\
\hline
\end{tabular}

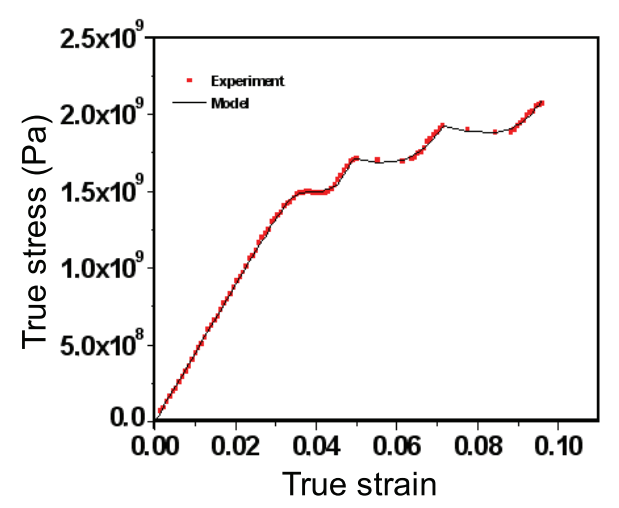

Fig. 8 Comparison of model prediction stressstrain curve and experimental results ${ }^{[32]}$ of $\mathrm{Zr}_{35} \mathrm{Ti}_{30} \mathrm{Co}_{6} \mathrm{Be}_{29}$ metallic glass (strain rate is $10^{-3} \mathrm{~s}^{-1}$ )

low value of $\Delta G^{*}$ obtained in this study.

Furthermore, while the process of structural relaxation is quite different, the value of activation energy for relaxation, $E_{\mathrm{r}}$ found in this study is not so far from that obtained using in situ X-ray diffraction $\operatorname{method}^{[43,44]}$.

According to recent experimental findings, two regimes of inhomogeneous deformation of BMG are generally distinguished: serrated and non-serrated. The transition between these two is controlled by the strain rate and temperature ${ }^{[45-47]}$. For each given temperature, there exists a critical strain rate at which this transition is observed, and vice versa. Furthermore, it has recently been established that the transition from serrated to non-serrated plastic flow is linked with a change of the deformation mechanism from jump-like (associated with shear banding process) to smooth (stick-slip process) $)^{[48-50]}$. The present rheological model is based on the deformation that proceeds via the simultaneous operation of multiple shear bands, with each band contributing to serration event. Hence, in the range of strain rate and temperature where the serration disappears and the deformation mechanism is different, the proposed 
model is no longer valid. Therefore, the adjustable obtained model parameters are plausible and nearly similar for the range of strain rate where the serration appears.

\section{Conclusions}

In this paper, we have successfully evaluated a micromechanism-inspired constitutive model describing the serrated flow nature of metallic glasses based on atomic structure of these materials and the corresponding micromechanisms of plastic flow. The effects of strain softening and the concept of crystallizationinduced hardening within the shear bands have been accounted for this model. The proposed model was compared with experimental data subjected to nanocompression loading. The model presents good quantitative agreement with experimental results and includes several characteristic physical parameters. We note that the somewhat large number of model parameters is a reflection of the physical nature of the plastic deformation process in metallic glasses.

\section{REFERENCES}

[1] Y. Kawamura, T. Shibata, A. Inoue and T. Masumoto, Scr. Mater. 37 (1997) 431.

[2] W.J. Kim, J.B. Lee and H.G. Jeong, Mater. Sci. Eng. A 428 (2006) 205.

[3] J. Schroers, T. Nguyen, S. O'Keeffe and A. Desai, Mater. Sci. Eng. A 449-451 (2007) 898.

[4] W.L Johnson, MRS Bull. 24 (1999) 42.

[5] C.A. Schuh, T.C. Hufnagel and U. Ramamurty, Acta Mater. 55 (2007) 4067.

[6] F. Spaepen, Acta Mater. 25 (1977) 407.

[7] A. Inoue, Acta Mater. 48 (2000) 279.

[8] C.T. Liu, L. Heatherly, D.S. Easton, C.A. Carmichael, J.H. Schneibel, C.H. Chen, J.L. Wright, M.H. Yoo, J.A. Horton and A. Inoue, Mater. Trans. A 29 (1998) 1811.

[9] W.L. Johnson and K. Samwer, Phys. Rev. Lett. 95 (2006) 195501.

[10] K. Hajlaoui, A.R. Yavari, B. Doisneau, A. LeMoulec, W.J. Botta, G. Vaughan, A.L. Greer, A. Inoue, W. Zhang and A. Kvick, Scr. Mater. 54 (2006) 1829.

[11] H.J. Leamy, T.T. Wang and H.S. Chen, Metall. Trans. 3 (1972) 699.

[12] C.A. Schuch, T.C. Hufnagel and U. Ramamurty, Acta Mater. 55 (2007) 4067.

[13] A. Inoue, W. Zhang, T. Tsurui, A.R. Yavari and A.L. Greer, Philos. Mag. Lett. 85 (2005) 221.

[14] A.H. Cottrell, Philos. Mag. 44 (1953) 829.

[15] K. Hajlaoui, B. Doisneau, A.R. Yavari, W.J. Botta, W. Zhang, G. Vaughan, A. Kvick, A. Inoue and A.L. Greer, Mater. Sci. Eng. A 449-451 (2007) 105.

[16] K. Hajlaoui, A.R. Yavari, A. LeMoulec, W.J. Botta, F.G. Vaughan, J. Das, A.L. Greer and Å. Kvick, J. Non-Cryst. Solids 35 (2007) 327.

[17] J. Fornell, E. Rossinyol, S. Surinach, M.D. Baro'et al, Scr. Mater. 62 (2010) 13.

[18] C.A. Schuh and T.G. Nieh. Acta Mater. 51 (2003) 87.

[19] W.H. Jiang and M. Atzmon, J. Mater. Res. 18 (2003) 755.
[20] G.P. Zhang, W. Wang, B. Zhang, J. Tan and C.S. Liu. Scr. Mater. 52 (2005) 1147.

[21] A.L. Greer and I.T. Walker, Mater. Sci. Forum $\mathbf{7 7}$ (2002) 386.

[22] W. Li, B. Wei, T. Zhnag, D. Xing, L. Zhang and Y. Wang. Intermetallics 15 (2007) 706.

[23] P. de Hey, J. Sietsma and A. van den Beukel, Acta Mater. 46 (1998) 5873.

[24] A.S. Argon, Acta Mater. 27 (1979) 47.

[25] K. Hajlaoui, Ph.D. Thesis, INPG Grenoble, 2005. (in France)

[26] J.C. Ye, J. Lu, Y. Yang and P.K. Liaw, Acta Mater. 57 (2009) 6037.

[27] A. Dubach, F.H. Dalla Torre and J.F. Loffler, Acta Mater. 57 (2009) 881.

[28] J.J. Kim, Y. Choi, S. Suresh and A.S. Argon, Science 295 (2002) 654.

[29] W.H. Jiang and M. Atzmon, Acta Mater. 51 (2003) 4095.

[30] W.H. Jiang and M. Atzmon, Scr. Mater. 54 (2006) 333.

[31] M.A. Yousfi, K. Hajlaoui, Z. Tourki and A.R. Yavari, J. Nanomater. 2011 (2011) No.36, DOI: $10.1155 / 2011 / 910962$.

[32] J. Dongchan, T.C. Gross and J.R. Greer, Int. J. Plast. 27 (2011) 858.

[33] C.Q. Chen, Y.T. Pei and J.T.M. De Hosson, Acta Mater. 58 (2010) 189.

[34] R. Huang, Z. Suo, J.H. Prevost and W.D. Nix, J. Mech. Phys. Solids 50 (2002) 1011.

[35] R. Ekambaram, P. Thamburaja and N. Nikabdullah, Mech. Mater. 40 (2008) 487.

[36] K. Russew and F. Sommer, J. Non-Cryst. Solids 319 (2003) 289.

[37] M. Bletry, Ph.D. Thesis, INPG Grenoble, 2004. (in France)

[38] M. Bletry, P. Guyot, Y. Brechet, J.J. Blandin and J.L. Soubeyroux, Intermetallics 12 (2004) 1051.

[39] B. van Aken, P. de Hey and J. Sietsma, Mater. Sci. Eng. A 278 (2000) 247.

[40] Y.L. Gao, J. Shen, J.F. Sun, D.M. Chen, G. Wang, R.H. Wang, D.W. Xing, H.Z. Xian and B. D. Zhou, Mater. Lett. 57 (2003) 2341.

[41] K. Kristiakova and P. Svec, Mater. Sci. Eng. 304 (2001) 343.

[42] J.J. Lewandowski and A.L. Greer, Nat. Mater. 5 (2006) 15.

[43] K. Hajlaoui, M.A. Yousfi, Z. Tourki, G. Vaughan and A.R. Yavari, J. Mater. Sci. 45 (2010) 3344.

[44] K. Hajlaoui, M.A. Yousfi, I. Ouelhazi, K. Georgarakis, Z. Tourki, G. Vaughan and A.R. Yavari, Philos. Mag. Lett. 91 (2011) 122.

[45] Y. Yokoyama, K. Fujita, A.R. Yavari and A. Inoue, Philos. Mag. Lett. 89 (2009) 322.

[46] H.M. Chen, J.C. Huang, S.X. Song, T.G. Nieh and J.S.C. Jang, Appl. Phys. Lett. 94 (2009) 141914

[47] A. Dubach, F.H. Dalla Torre and J.F. Loffler, Philos. Mag. Lett. 87 (2007) 695.

[48] B.A. Sun, S. Pauly, J. Tan, M. Stoica, W.H. Wang, U. Kuhn and J. Eckert, Acta Mater. 60 (2012) 4160

[49] D. Klaumuenzer, R. Maass and J.F. Loffler, J. Mater. Res. 26 (2011) 1453.

[50] F.H. Dalla Torre, D. Klaumünzer, R. Maaß and J.F. Löffler, Acta Mater. 58 (2010) 3742 